\title{
$\beta$ Blockers and the failing heart: is it time for a U-turn?
}

\author{
Y Bashir, W J McKenna, A J Camm
}

Since the introduction of $\beta$ adrenoceptor antagonists into clinical practice approximately 30 years ago, these drugs have been regarded as being contraindicated in patients with severely depressed ventricular function because of the risk of precipitating haemodynamic deterioration. It may therefore seem both surprising and paradoxical that the idea of using $\beta$ blockers as a primary therapy for congestive heart failure to improve symptoms and prognosis has gained considerable ground recently. This fundamental shift in opinion has come about for several reasons. (a) There is increasing evidence that the deleterious long-term effects of excessive sympathetic stimulation on cardiac mechanical performance and electrical stability may outweigh any immediate benefits of inotropic support to the failing myocardium, thus providing a clearer rationale for the use of $\beta$ adrenoceptor antagonists. (b) Subgroup analysis of postinfarction $\beta$ blocker trials has shown that the greatest reductions in mortality were seen in patients with mild or moderate heart failure. (c) Most studies of low dose $\beta$ blockade in patients with congestive heart failure showed sustained improvements in functional capacity, haemodynamic indices, and control of ventricular arrhythmias. (d) By contrast, longterm treatment with $\beta$ adrenoceptor agonists and other inotropes has failed to produce such beneficial responses and there is now clear evidence that these drugs increase mortality. (e) The success of angiotensin converting enzyme inhibitors has lent powerful support to the general principle that blockade of "compensatory" neurohormonal mechanisms may be a beneficial in the treatment of heart failure.

\section{Department of Cardiological} Sciences, St George's Hospital, Medical School, London Y Bashir W J McKenna A J Camm Correspondence to: Dr Y Bashir, Department of Cardiological Sciences, Jenner Wing, St George's Hospital Medical School, Cranmer Terrace, London, SW17 0RE

Accepted for publication 3 February 1993

\section{Rationale for $\beta$ blocker treatment in heart failure}

It is now recognised that activation of the sympathetic nervous system plays an extremely complex part in the pathophysiology of heart failure, exerting both beneficial and adverse effects at the same time. Inotropic support to failing myocardium may help to maintain circulatory homoestasis but with continuous adrenergic stimulation this response soon becomes blunted because of progressive desensitisation of the $\beta$ receptor pathway. The loss of sensitivity is attributable both to $\beta$ receptor downregulation and changes in the regulatory $G$ proteins that $\vec{\circ}$ uncouple the receptors from adenylate cyclase, their second messenger. ${ }^{12}$ The diminishing benefits of inotropic stimulation are offset by the deleterious effects of chronically increased sympathetic tone on myocardial structure and metabolism, ventricular $\vec{\infty}$ mechanical performance, and susceptibility to life-threatening arrhythmias. This shifting balance between the favourable and adverse influences of the sympathetic nervous system is the key to understanding how $\beta$ blockers $\vec{c}$ can be used to obtain clinical benefit in $\omega$ patients with heart failure.

CATECHOLAMINE MEDIATED CARDIOTOXICITY Chronically raised catecholamine concentrations are directly injurious to the myocardium and may contribute to the progression of $\Rightarrow$ underlying heart disease. ${ }^{3}$ Rabbits and patients treated with pharmacological doses of noradrenaline developed myocardial necrosis and impaired ventricular function, ${ }^{4}$ and a reversible cardiomyopathy with similar histological features was seen in association with phaeochromocytomas. ${ }^{5}$ Several mechanisms could be involved including intracellular calcium accumulation, energy depletion, generation of free radicals by catecholamine $\frac{9}{9}$ metabolites such as adrenochrome, and $D$ chronic subendocardial ischaemia. ${ }^{6-8}$ It is assumed that $\beta$ blockers may afford some $N$ protection against catecholamine mediated myocardial damage, though there is no experimental evidence for this.

\section{HAEMODYNAMIC BENEFITS}

Despite their negative inotropic properties, $\beta$ blockers could improve the mechanical performance of the failing heart by various mechanisms. Correction of regional wall motion abnormalities resulting from inhomogeneities $\mathbb{\mathbb { D }}$ of cardiac sympathetic innervation is one possibility. Loss of normal temporal coordination of myocardial contraction and relaxation is a common finding in patients with chronic heart failure, and is probably as important a determinant of impaired ventricular function as any absolute reduction in contractility. ${ }^{9}$ The asynergy is partly due to patchy destruction of nerve terminals and disruption of the normally uniform sympathetic innervation. In dogs asynchronous wall motion was produced 
by regional cardiac denervation, leading to considerable deterioration in overall ventricular function, but these adverse effects were reversed by $\beta$ blockade. ${ }^{10} \beta$ Blockers might also improve contractility in patients with abnormally prolonged mechanical restitution by slowing heart rate and thereby allowing systole to occur in the more advantageous plateau portion of the restitution curve. ${ }^{11}$ Lengthening of the cardiac cycle may also compensate for abnormalities of diastolic function. For example, $\mathrm{Ng}$ and Gibson found that the effective ventricular filling time is reduced to less than $200 \mathrm{~ms}$ in approximately $25 \%$ of patients with impaired left ventricular function by the combined effects of rapid heart rates and persistence of mitral regurgitation beyond mitral valve opening. ${ }^{12}$ Finally, removal of $\beta$-receptor stimulation may indirectly reduce vasoconstriction and fluid retention by secondary effects on the reninangiotensin system and vasopressin release.

\section{SYMPATHETIC NERVOUS SYSTEM AND ARRHYTHMOGENESIS}

The sympathetic nervous system is also thought to play a key part in the genesis of ventricular arrhythmias by potentiating abnormal automaticity, triggered activity, and reentry in diseased myocardium ${ }^{13}$; the combination of increased sympathetic tone and myocardial ischaemia seems to be a particularly potent trigger for malignant ventricular arrhythmias. $\beta$ Blockers, by virtue of their anti-ischaemic and anti-adrenergic properties, have been shown to be uniquely cardioprotective in this setting whereas conventional class I and class III antiarrhythmic drugs are usually ineffective or even arrhythmogenic. ${ }^{14}$ This is potentially of considerable importance because sudden death accounts for nearly half of total mortality in chronic heart failure ${ }^{15}$ and the lethal rhythm disturbance is a ventricular tachycardia in approximately $80 \%$ of patients with underlying coronary artery disease (by far the commonest cause of heart failure in the general population). ${ }^{1617}$

\section{Clinical experience with $\beta$ blockers in congestive heart failure}

Since Waagstein et al's pioneering report in $1975^{18}$ numerous groups have investigated the effects of $\beta$-adrenoceptor antagonists in patients with congestive heart failure and left ventricular dysfunction. Most of the early studies were confined to the relatively uncommon condition of idiopathic dilated cardiomyopathy, but more recently $\beta$ blockers have been evaluated in patients with heart failure secondary to other causes including coronary artery disease. The table summarises the results from 16 separate reports published since 1980 six open studies and 10 randomised controlled trials) of 372 patients, of whom approximately $80 \%$ received active treatment with $\beta$ blockers. ${ }^{19-35}$ Though the studies differed in design, duration of treatment, choice of $\beta$ blocker, and patient characteristics, the findings were fairly consistent with improvements in symptoms, exercise capacity, left ventricular function, and central haemodynamic and neurohormonal indices. The benefits seem to have been maintained during long-term follow up for at least two years, and late withdrawal of chronic $\beta$-blocker treatment usually resulted in clinical and haemodynamic deterioration within a few months. ${ }^{25} 36$ Objective increases in exercise tolerance were observed less consistently than symptomatic improvement, possibly because of the widespread use of maximal exercise testing which may be a less reliable indicator of functional capacity than endurance at submaximal work loads. ${ }^{35}$ The changes in resting left ventricular function were superficially very impressive: a pooled analysis of data from 12 studies (162 patients) showed an increase in ejection fraction from $26 \%$ to $37 \%,{ }^{37}$ which is considerably greater than has been seen with ACE inhibitors, digoxin, vasodilators, and inotropic drugs. The significance of this finding has been justifiably questioned because none of the other agents slow the heart rate to the same extent as $\beta$ blockers, but in at least one study the

\begin{tabular}{|c|c|c|c|c|c|c|c|c|c|c|}
\hline \multirow[b]{2}{*}{ Reference } & \multirow[b]{2}{*}{ Design } & \multirow[b]{2}{*}{ Patients* } & \multirow[b]{2}{*}{ Aetiology } & \multirow[b]{2}{*}{ Drug } & \multirow[b]{2}{*}{$\begin{array}{l}\text { Duration } \\
\text { (mnth) }\end{array}$} & \multicolumn{5}{|l|}{ Changes in } \\
\hline & & & & & & Symptoms & $\begin{array}{l}\text { Exercise } \\
\text { tolerance }\end{array}$ & $L V E F$ & $\begin{array}{l}\text { Central } \\
\text { haemo- } \\
\text { dynamics }\end{array}$ & $\begin{array}{l}\text { Intolerance } \\
(\%)\end{array}$ \\
\hline Swedberg et al ${ }^{19}$ & Open & $28(28)$ & $\mathrm{DCM}$ & Various & 23 & + & + & + & NA & $1 / 28(4)$ \\
\hline Ikram et al 20 & Double blind (C) & $15(15)$ & DCM & Acebutolol & 1 & \pm & - & \pm & NA & $1 / 17(6)$ \\
\hline Currie et al 21 & Double blind (C) & $10(10)$ & $\mathrm{DCM}, \mathrm{CAD}$ & Metoprolol & 1 & \pm & - & \pm & - & $0 / 10(0)$ \\
\hline Engelmeier et al ${ }^{22}$ & Double blind $(\mathrm{P} / \mathrm{C})$ & $25(21)$ & $\mathrm{DCM}$ & Metoprolol & 12 & + & + & + & NA & $1 / 21(5)$ \\
\hline Anderson et al ${ }^{23}$ & Double blind (P) & $50(25)$ & DCM & Metoprolol & 19 & + & \pm & NA & NA & $3 / 25(12)$ \\
\hline Waagstein et al 24 & Open & $13(13)$ & CAD, Valv & Metoprolol & 12 & + & + & + & + & NA \\
\hline Waagstein et al 2526 & Open & 33 (33) & DCM & Metoprolol & 16 & + & + & + & + & $7 / 33(21)$ \\
\hline Eichhorr et al 27 & Open & $15(15)$ & DCM,CAD & Bucindolol & 3 & NA & NA & + & + & $0 / 15(0)$ \\
\hline Das Gupta et al ${ }^{28}$ & Open & 17 (17) & CAD & Carvedilol & 2 & + & + & + & + & $3 / 17$ (18) \\
\hline Pollock et al ${ }^{29}$ & Double blind $(P)$ & $19(12)$ & DCM,CAD & Bucindolol & 3 & + & + & + & + & $0 / 19$ (0) \\
\hline Leung et al ${ }^{30}$ & Double blind (C) & $12(12)$ & $\mathrm{DCM}$ & Labetalol & 2 & + & + & NA & + & $0 / 12(0)$ \\
\hline Nemanich et al ${ }^{31}$ & Open & $10(10)$ & $\mathrm{DCM}, \mathrm{CAD}$ & Metoprolol & 2 & + & + & + & NA & $2 / 10(20)$ \\
\hline Woodley et al ${ }^{32}$ & Double blind $(\mathrm{P})$ & $50(30)$ & DCM,CAD & Bucindolol & 3 & + & \pm & + & + & $1 / 51(2)$ \\
\hline Fisher et al ${ }^{33}$ & Double blind (P) & $35(17)$ & CAD & Metoprolol & 6 & + & NA & + & NA & NA \\
\hline Paolisso et al ${ }^{34}$ & Double blind (C) & $10(10)$ & DCM,Valv & Metoprolol & 3 & + & + & + & NA & $0 / 10(0)$ \\
\hline Olsen ${ }^{35}$ & Double blind (P) & $30(18)$ & DCM & Carvedilol & 4 & NA & + & + & NA & NA \\
\hline
\end{tabular}

C, Crossover trial; $\mathrm{P}$, parallel group study; DCM dilated cardiomyopathy; CAD coronary artery disease; Valv = valvar heart disease

C, Crossover trial; $\mathrm{P}$, parallel group study; $\mathrm{DCM}$ dilated cardiomyopathy; CAD
$+=$ improvement; $\pm=$ no change $-=$ deterioration; $\mathrm{NA}=$ data not available.

$+=$ improvement; $\pm=$ no change $-=$ deterioration;
$\star$ Number receiving $\beta$ blockers is given in parentheses.

^Number receiving $\beta$ blockers is given in parentheses. deteriorated acutely, therefore the total number of patients may be greater than the number in the final study report). 
improvement in ejection fraction was observed despite the use of atrial pacing to achieve matched heart rates before and after treatment. ${ }^{27}$ Several groups have examined changes in central haemodynamic indices and have shown reductions in ventricular filling pressures usually accompanied by increases in cardiac index. ${ }^{25-2932}$ Recently, Eichorn et al conducted a meticulous investigation of the haemodynamic effects of 3 months' treatment with bucindolol in patients with heart failure of various aetiologies. ${ }^{27}$ Care was taken to avoid the confounding influence of changes in heart rate and loading conditions. All measurements were performed at matched atrial pacing rates and indices of cardiac performance that were relatively loud independently were derived. Bucindolol augmented contractility as assessed from the end systolic pressure-volume relation and the peak positive $\mathrm{dP} / \mathrm{dt}$ end diastolic volume relation, and also improved myocardial relaxation as shown by a reduction in the time constant of left ventricular isovolumic relaxation. Furthermore, these beneficial changes in systolic and diastolic function were achieved without any rise in myocardial oxygen consumption, indicating an improvement in the efficiency of myocardial energetics. ${ }^{26}{ }^{27}$ Even more significantly, the haemodynamic benefits have usually been accompanied by reductions in neurohormonal activity, particularly a fall in plasma noradrenaline concentration, ${ }^{26} 323839$ one of the most powerful prognostic indicators in patients with heart failure. ${ }^{40}$ Though much attention has been paid to the phenomenon of $\beta$-receptor up regulation, this does not correlate with the time course or degree of clinical improvement, and is probably of little significance because the extra receptors remain pharmacologically blocked. ${ }^{25}$

Several general points have emerged from these studies. Treatment must be started at an extremely low dose (for example, metoprolol $6.25 \mathrm{mg}$ twice a day which is increased gradually to therapeutic levels over several weeks. Clinical improvement may take several months to become apparent and is sometimes preceded by a temporary deterioration, ${ }^{925}$ which possibly accounts for the negative findings of the two shortest studies (each lasted only one month)..$^{20}$ Even with cautious dosing, some patients have to be withdrawn because of worsening heart failure, bradycardia, or hypotension: in studies that provided details, the overall incidence of acute intolerance was surprisingly low at around $7 \%$ (range $0-21 \%$ ) with no directly attributable deaths (see table). Dramatic haemodynamic deterioration is occasionally seen, ${ }^{41}$ but fortunately such cases seem to be rare. It may be prudent to avoid such treatment in patients with decompensated or severe (New York Heart Association class IV) heart failure, but even some of these seem to tolerate $\beta$ blockade without problems and derive long-term benefit. $^{1925}$ Indeed, one group has even reported the successful use of low-dose metoprolol in patients with end stage heart failure requiring inotropic support. ${ }^{42}$ As in the early days of ACE inhibitors, patients have generally been admitted for the initial doses, and the safety and feasibility of starting treatment on an outpatient basis requires further evaluation.

It is crucially important to know whether $\beta$ blockers work equally well in heart failure with aetiologies other than idiopathic dilated cardiomyopathy. One recent report suggested that they might be only marginally effective in heart failure secondary to ischaemic heart disease, ${ }^{32}$ but at least three other studies have shown improvements comparable to those obtained in patients with cardiomyopathy. ${ }^{24} 2833$ Moreover, from a prognostic point of view, patients with coronary artery disease might obtain cardioprotective benefits from $\beta$ blockade even in the absence of any objective improvement in functional and haemodynamic status.

Another unanswered question is whether or not there are any significant differences between individual $\beta$ adrenoreceptor antagonists. Most of the early studies used metoprolol, which is relatively selective for $\beta_{1}$ receptors, but attention has recently switched to a new generation of $\beta$ blockers with vasodilating properties such as bucindolol and carvedilol. These agents have been developed in the hope that they might be less likely to precipitate acute haemodynamic deterioration than conventional $\beta$ blockers. To date, no obvious differences have emerged in therapeutic efficacy or tolerance but there has never been a direct comparison.

\section{$\beta$ Blockers and ventricular arrhythmias}

Clinical experience with $\beta$ blockers in the management of ventricular arrhythmias has further strengthened the cases for their use in patients with heart failure. It is well recognised that the safety and the efficacy of conventional antiarrhythmic drugs is much reduced when ventricular function is impaired..$^{43}$ This is partly because their electrophysiological effects are reversed by sympathetic stimulation. ${ }^{44}$ In contrast, several groups found that adjuvant treatment with $\beta$ blockers was highly effective for the control of malignant ventricular arrhythmias in patients with severe left ventricular dysfunction in whom numerous other antiarrhythmic drugs or drug combinations had failed. ${ }^{45-48} \beta$ blockers have been successfully combined with both class I agents and amiodarone and, as in the heart failure studies, the incidence of haemodynamic intolerance was surprisingly low despite generally higher doses.

\section{Do $\beta$ blockers prolong survival in chronic heart failure?}

There have been important advances in the symptomatic treatment of congestive heart failure, but prolonging survival remains a major therapeutic challenge. In recent multicentre trials mortality among patients with mild or moderate heart failure treated with ACE inhibitors and diuretics was $35-40 \%$ at 
four years. ${ }^{490}$ This death rate is not only caused by progressive heart failure but also by a high incidence of sudden death in haemodynamically stable patients ${ }^{15}$; the classification and causes of these sudden deaths have been extensively debated, but in patients with underlying coronary artery disease the commonest mechanism is a sustained ventricular tachycardia (possibly triggered by acute myocardial ischaemia). ${ }^{16}{ }^{17}$ From a prognostic standpoint, the use of $\beta$ blockers seems particularly attractive to prevent or slow catecholamine-mediated deterioration in ventricular function, while at the same time protecting against the development of lethal arrhythmias.

Though none of the studies performed so far was large enough to provide meaningful data on survival, it is notable that $\beta$ blockade consistently improved the key prognostic indices such as left ventricular ejection fraction, plasma noradrenaline concentration, exercise capacity, and ventricular arrhythmias. Supportive evidence for a beneficial effect of $\beta$ blockers on survival in chronic heart failure has emerged from subgroup analysis of randomised post-infarction trials. In the Beta-Blocker Heart Attack Trial, the greatest reduction in cardiac mortality in the group receiving propranolol was among patients with evidence of heart failure before randomisation $^{51}$; in particular, there was a striking $47 \%$ reduction in the incidence of sudden death in this high-risk cohort compared with only a $13 \%$ reduction in patients without a history of heart failure. Analysis of the Norwegian timolol trial gave similar results. ${ }^{52}$ By contrast, conventional antiarrhythmic drugs (including amiodarone) seem to be ineffective for preventing sudden death in post-infarction patients with left ventricular dysfunction or chronic heart failure. ${ }^{53-55}$

Indirect support for a beneficial effect of $\beta$ blockers on survival is provided by the disappointing clinical results obtained with $\beta$ adrenoceptor stimulation. Long-term treatment with $\beta$ agonists and other inotropes such as the phosphodiesterase inhibitors not only fails to produce sustained symptomatic and haemodynamic improvements but also is associated with a definite increase in mortality. ${ }^{5657}$ The $\beta$-receptor partial agonist xamoterol increased mortality in patients with severe heart failure. ${ }^{58}$ Some have attributed this deleterious effect to predominant $\beta$ antagonist activity in the face of high resting sympathetic tone, but Holter monitoring disclosed an increase in heart rate (that is, $\beta$ receptor stimulation) during the early hours of the morning, when patients are at their most vulnerable to life-threatening cardiac events. Similarly, $\beta$ blockers with intrinsic sympathomimetic activity generally have not been found to reduce mortality in survivors of infarction. ${ }^{59}$

\section{Conclusions}

An increasing weight of experimental and clinical observations suggest that the long- term effects of the sympathetic nervous system in chronic heart failure are predominantly deleterious, and that judicious use of $\beta$-blockade may produce sustained clinical and haemodynamic improvements in most patients as well as protecting against the development of malignant ventricular arrhythmias; with appropriate dosing the risk of acute haemodynamic deterioration is small. The possibility of publication bias leading to selective reporting of favourable results needs to be considered as does the widespread use of pragmatic (rather than intention to treat) analysis. Even allowing for these potential confounding influences, the results are very striking and resemble those obtained with ACE inhibitors. Both theoretical considerations and indirect evidence suggest that these benefits may lead to a reduction in mortality, particularly among patients with underlying coronary artery disease. Accordingly, the time has arrived for definitive, large-scale, controlled trials to assess the long-term safety and efficacy of $\beta$ blockers in general heart failure populations and, most importantly of all, their impact on survival. Some investigations including the Metoprolol in Dilated Cardiomyopathy Trial and the Cardiac Insufficiency Bisoprolol Study (CIBIS) are already in progress and others are planned. The SOLVD (Studies of Left Ventricular Dysfunction) investigators are considering a proposal for a multicentre study with a factorial design to evaluate simultaneously two different $\beta$ blockers and oral magnesium replacement. As yet, very few British centres are participating in this research or indeed have any clinical experience with the use of $\beta$ blockers in heart failure. However, should these multicentre trials confirm the promise of $\beta$ blockade, we may witness a remarkable U-turn in the routine management of chronic heart failure before the end of the century. In an era when enormous resources are earmarked for the development of new cardiovascular drugs it would be ironic, but by no means unprecedented, to discover that a potentially important and valuable treatment has been staring us in the face.

1 Fowler MB, Laser JA, Hopkins GL, Minobe W, Bristow MR. Assessment of the beta-adrenergic receptor pathway in the intact failing human heart: progressive receptor downregulation and subsensitivity to agonist response. Circulation 1986;74:1290-302.

2 Brodde OE. Pathophysiology of the beta-adrenoceptor system in chronic heart failure: consequences for treatsystem in chronic heart falure: consequences for treatment with agonists, partial agonist

3 Haft II. Cardiovascular injury induced by sympathetic catecholamines. Prog Cardiovasc Dis 1974;17:73-85.

4 Gavras H, Kremer D, Brown J, et al. Angiotensin and norepinephrine-induced myocardial lesions: experimental and clinical studies in rabbits and man. Am Heart $\mathcal{f}$ 1975;89:321-32.

5 Van Vliet PD, Burchell HB, Titus JL. Focal myocarditis associated with pheochromocytoma. $N$ Engl $f \mathrm{Med}$ 1966;274:1102-8

6 Fleckenstein A, Janke J, Doring HJ, Pachinger O. Calcium overload as the determinant factor in the production of catecholamine-induced myocardial lesions. Rec $A d v$ Stud Cardiac Struct Metab 1973;2:455-68.

7 Simons M, Downing SE. Coronary vasoconstriction and catecholamine cardiomyopathy. Am Heart $\mathcal{F} 1985 ; 109$ : 297-303. 
8 Yates JC, Beamish RE, Dhalla NS. Ventricular dysfunction and necrosis produced by adrenochrome metabolite of epinephrine: relationship to pathogenesis of cate210-21.

9 Brutsaert DL. Nonuniformity: a physiologic modulator of contraction and relaxation of the normal heart. $7 \mathrm{Am}$ Contraction and relaxation

10 Knight DR, Shen YT, Thomas IX, Randall WC, Vatner $\mathrm{SF}$. Sympathetic activation induces asynchronous contraction in awake dogs with regional denervation. $\mathrm{Am} \mathcal{F}$ Physiol 1988;255:H358-65.

11 Pidgeon JG, Miller AH, Noble MIM, Papdoyannis D Seed WA. The relationship between the strength of the human heart beat and the interval between beats. Circulation 1982;65:1404-10.

$12 \mathrm{Ng} \mathrm{KS}$, Gibson DG. Impairment of diastolic function by shortened filling period in severe left ventricular disease. Br Heart $71989 ; 62: 246-52$.

13 Podrid PJ, Fuchs T, Candinas R. Role of the sympathetic nervous system in the genesis of ventricular arrhythmia. nervous system in the genesis of ventric
Circulation 1990;82(Suppl I): 103-13.

14 Venditti FJ, Garan H, Ruskin JN. Electrophysiologic effects of beta-blockers in ventricular arrhythmias. $A m$ Cardiol 1987;60:3D-9D.

15 Bigger JT. Why patients with congestive heart failure die: arrhythmias and sudden cardiac death. Circulation 1987 75(Suppl IV):28-35.

16 Luu M, Stevenson WG, Stevenson LW, Baron K, Walden J. Diverse mechanisms of unexpected cardiac arrest in advanced heart failure. Circulation 1989;80:1675-80.

17 de Luna AB, Coumel P, Leclercq JF. Ambulatory sudden cardiac death: mechanisms of production of fata arrhythmia on the basis of data from 157 cases. Am Heart 7 1989;117:151-9.

18 Waagstein F, Hjalmarson A, Varnauskas E, Wallentin I. Effect of chronic beta-adrenergic receptor blockade in congestive cardiomyopathy. $\mathrm{Br}$ Heart $\mathcal{f} 1975 ; 37$ : 1022-36.

19 Swedberg K, Hjalmarson A, Waagstein F, Wallentin I. Beneficial effects of long-term beta-blockade in congestive cardiomyopathy. Br Heart $\mathcal{f} 1980 ; 44: 117-33$.

20 Ikram H, Fitzpatrick D. Double-blind trial of chronic ora beta-blockade in congestive cardiomyopathy. Lance 1981;ii:490-2.

21 Currie PJ, Kelly MJ, McKenzie A, et al. Oral betaadrenergic blockade with metoprolol in chronic severe dilated cardiomyopathy. $\mathcal{F} \mathrm{Am}$ Coll Cardiol 1984; 3:203-9.

22 Engelmeier RS, O’Connell JB, Walsh R, Rad N, Scanlon PJ, Gunnar RM. Improvement in symptoms and exercise tolerance by metoprolol in patients with dilated cardiomyopathy: a double-blind, randomized, placebocontrolled trial. Circulation 1985;72:536-46.

23 Anderson $\mathrm{J}$, Lutz JR, Gilbert EM, et al. A randomized trial of low-dose beta-blockade therapy for idiopathic dilated cardiomyopathy. $A m \mathcal{F}$ Cardiol 1985;55:471-5.

24 Waagstein F, Blomstrom-Lundqvist C, Andersson B Hjalmarson A, Wallentin I. Long-term effects of metoprolol in severe heart failure due to ischaemic cardiomyopathy, primary valve disease and diabetes [abstr] Circulation 1987;76(Suppl IV):IV-358.

25 Waagstein F, Caidahl K, Wallentin I, Bergh $\mathrm{CH}$, Hjalmarson A. Long-term beta-blockade in dilated cardiomyopathy: effects of short and long-term metoprolol treatment followed by withdrawal and readministration of metoprolol. Circulation 1989;80:551-63.

26 Andersson B, Blomstrom-Lundqvist C, Hedner $T$ Waagstein F. Exercise hemodynamics and myocardia metabolism during long-term beta-adrenergic blockade metabolism during long-term beta-adrenergic blockade in severe

27 Eichhorn EJ, Bedotto JB, Malloy CR, et al. Effect of beta-adrenergic blockade on myocardial function an energetics in congestive heart failure. Circulation 1990; 82:473-83.

28 Das Gupta P, Broadhurst P, Raftery EB, Lahiri A. Value of carvedilol in congestive heart failure secondary to

29 Pollock SG, Lystash J, Tedesco C, Craddock G, Smucker ML. Usefulness of bucindolol in congestive heart failML. Usefulness of bucindolol in
ure. Am $₹$ Cardiol 1990;66:603-7.

30 Leung WH, Lau CP, Wong CK, Cheng CH, Tai YT, Lim SP. Improvement in exercise performance and hemodynamics by labetalol in patients with idiopathic hemodynamics by labetalol in patients with idiopathic

31 Nemanich JW, Veith RC, Abrass IB, Stratton JR Effects of metoprolol on rest and exercise cardiac function and plasma catecholamines in chronic congestive heart failure secondary to ischaemic or idiopathic cardiomyopathy. Am F Cardiol 1990;66:843-8.

32 Woodley SL, Gilbert EM, Anderson JL, et al. Beta-blockade with bucindolol in heart failure caused by ischaemic versus idiopathic dilated cardiomyopathy. Circulation 1991;84:2426-41.

33 Fisher ML, Gottlieb SS, Hamilton B, et al. Beneficial effects of metoprolol in congestive heart failure associated with coronary artery disease: a randomized trial ed with coronary artery disease: a rand

34 Paolisso G, Gambardella A, Marrazzo G, et al. Metabolic and cardiovascular benefits deriving from beta-adrenergic blockade in chronic congestive heart failure. $A m$ Heart ₹ 1992;123:103-10.

35 Olsen SL Yanowitz FG, Gilbert EM, et al. Beta-blocker related improvement in submaximal exercise tolerance in heart failure from idiopathic dilated cardiomyopathy [abstr]. $\mathcal{F} \mathrm{Am}$ Coll Cardiol 1992;19:146.

36 Swedberg K, Hjalmarson A, Waagstein F, Wallentin I. Adverse effects of beta-blockade withdrawal in patient with congestive cardiomyopathy. Br Heart $\mathcal{f}$ 1980;44: $134-42$.

37 Hjalmarson A, Waagstein F. New therapeutic strategies in chronic heart failure: challenge of long-term betablockade. Eur Heart f 1991;12(suppl F):63-9.

38 Anderson JL, Gilbert EM, O'Connell JB, et al. Long-term (2 year) beneficial effects of beta-adrenergic blockade with bucindolol in patients with idiopathic dilated cardiomyopathy. F Am Coll Cardiol 1991;17:1373-81.

39 Bristow MR, Olsen SL, Gilbert EM, et al Beta-blockade with carvedilol selectively lowers cardiac adrenergic drive in the failing human heart [abstr]. $f \mathrm{Am} \mathrm{Coll}$ drive in the failing
Cardiol $1992 ; 19: 146 \mathrm{a}$.

40 Cohn JN, Levine TB, Olivari MT, et al. Plasma norepinephrine as a guide to prognosis in patients with con gestive heart failure. N Engl $\mathcal{F}$ Med 1984;311:819-23.

41 Hoffbrand BI. Beta-adrenergic blockade in congestive cardiomyopathy. Lancet 1980;i:1031.

42 Patten RD, Fisher ML, Greenberg NL, Gottlieb SS. Betablocker therapy in inotropic supported congestive heart failure patients [abstr]. Circulation 1992;86(suppl. I): 645

43 Pratt CM, Eaton T, Francis $M$, et al. The inverse relationship between baseline left ventricular ejection fraction and outcome of antiarrhythmic therapy: a dangerous imbalance in the risk-benefit ratio. Am Heart $\mathcal{F} 1989$; 118:433-40.

44 Morady F, Kou WH, Kadish AH, et al. Antagonism of quinidine's electrophysiologic effects by epinephrine in patients with ventricular tachycardia. $\mathcal{F}$ Am Coll Cardiol 1988;12:388-94.

45 Brodsky MA, Allen BJ, Bessen M, Luckett CR, Siddiqui $R$, Henry WL. Beta-blocker therapy in patients with ventricular tachyarrhythmias in the setting of left ventricular dysfunction. Am Heart $\mathcal{F}$ 1988;115:799-807.

46 Tonet J, Frank G, Fontaine G, Grosgogeat Y. Efficacy and safety of low doses of beta-blocker agents combined with amiodarone in refractory ventricular tachycardia. PACE 1988;11:1984-9.

47 Leclercq JF, Leenhardt A, Lemarec $\mathrm{H}$, et al. Predictive value of electrophysiologic studies during treatment of ventricular tachycardia with the beta-blocking agent nadolol. F Am Coll Cardiol 1990;16:413-7.

48 Bashir Y, Paul VE, Griffith MJ, et al. A prospective study of the efficacy and safety of adjuvant xamoterol and metoprolol in combination with amiodarone for resis tant ventricular tachycardia in patients with impaire left ventricular function. Am Heart $\mathcal{F}$ 1992;124:1233-41.

49 Cohn JN, Johnson G, Ziesche S, et al. A comparison of enalapril with hydralazine-isosorbide dinitrate in the treatment of chronic congestive heart failure. $N$ Engl Med 1991;325:303-10.

50 The SOLVD Investigators. Effect of enalapril on survival in patients with reduced left ventricular ejection fraction and congestive heart failure. $N$ Engl $f$ Med 1991; 325:293-302.

51 Chadda $\mathrm{K}$, Goldstein $S$, Byington $R$, Curb JD. Effect of propranolol after acute myocardial infarction in patients with congestive heart failure. Circulation 1986;73: 503-10.

52 The Norwegian Multicenter Study Group. Timololinduced reduction in mortality and reinfarction in patients surviving acute myocardial infarction. $N$ Engl $f$ Med 1981;304:801-7.

53 Cardiac Arrhythmia Suppression Trial (CAST) Investigators. Preliminary report: effect of encainide and flecainide on mortality in a randomized trial of arrhythmia suppression after myocardial infarction. $N$ Engl ff Med 1989;321:406-12.

54 Pfisterer M, Burkart F, Kiowski W. Protective effect of amiodarone after myocardial infarction in patients with complex ventricular arrhythmias and preserved but not impaired LV function [abstr]. Circulation 1990;82 (suppl iII): 197

55 Nicklas JM, McKenna WJ, Stewart RA, et al. Prospective, double-blind, placebo-controlled trial of low-dose amiodarone in patients with severe heart failure and asymp tomatic frequent ventricular ectopy. Am Heart $\mathcal{f} 1991$; 122:1016-21.

56 Yusuf S, Teo KK. Inotropic agents increase mortality in patients with congestive heart failure [abstr]. Circulation 1990;82(suppl III):673a.

57 Packer M, Carver JR, Rodeheffer RJ, et al. Effect of oral milrinone on mortality in severe chronic heart failure. N Engl $₹$ Med 1991;325:1486-75.

58 The Xamoterol in Severe Heart Failure Study Group. Xamoterol in severe heart failure. Lancet 1990;336:1-6.

59 Yusuf S, Peto R, Lewis J, Collins R, Sleight P. Betablockade during and after myocardial infarction: an overview of the randomised trials. Prog Cardiovasc Dis 1985;25:335-71. 